\title{
TORQUE TRANSMISSION TIME-CONSTANT EXAMINATION OF A DISK- TYPE MAGNETORHEOLOGICAL CLUTCH
}

\author{
SÁNDOR MESTER ${ }^{* 1}$ AND ISTVÁN SZALAI ${ }^{1}$ \\ ${ }^{1}$ Institute of Mechatronics Engineering and Research, University of Pannonia, Gasparich Márk utca 18/A, \\ Zalaegerszeg, 8900, HUNGARY
}

\begin{abstract}
In this paper, the torque transmission time-constant of a simple disk-type magnetorheological (MR) clutch is investigated. By using MR fluid, controlled torque transmission can be easily implemented, facilitating the widespread use of similar systems. In order to describe the dynamical properties of the system, time constants were measured at different speeds and magnetic inductions. The time constants were derived by fitting an exponential function to the data.
\end{abstract}

Keywords: magnetorheological fluid, clutch, torque transmission

\section{Introduction}

The implementation of intelligent materials has significantly increased not only in everyday life, but in the industrial environment as well. Magnetorheological fluids are suspensions that consist of at least two phases, whose apparent viscosity changes quickly (within $20-30 \mathrm{~ms}$ ) in the presence of an external magnetic field. The suspension usually consists of small ferromagnetic particles of approximately $10 \mu \mathrm{m}$ in diameter dispersed in oil. Usually surface active agents are also present in the fluid to prevent the particles from being attracted to each other. In the presence of an external magnetic field, the particles gain an induced dipole moment and form pairs, followed by chain-like structures. If the fluid is exposed to shearing, these chain-like structures oppose each other leading to an increase in apparent viscosity which can be used in shock absorbers, torque transmission, superfinishing of optical lenses and civil engineering [1-4]. In addition to the rapid change in apparent viscosity, its low power requirement makes MR fluid ideal for use in semiactive shock absorbers and variable torque-transmission clutches.

The most basic forms of magnetorheological clutches are the disk and cylindrical types. The differences between the two types are the transmittable torque and the volume of the idling waste. A stream of particles is present in disk-type clutches due to the centrifugal force. In the cylindrical type, the effect is less significant $[5,6]$. This study focuses on a disk-type clutch with a welldefined mathematical model [7].

\footnotetext{
*Correspondence: hollosi.janos@sze.hu
}

\section{Experimental}

The model of our magnetorheological clutch is shown in Fig. 1. The clutch consisted of the following main components: 1 . DC servomotor with a gearbox; 2 . toothed belt drive with $1: 1$ gear ratio; 3 . input or drive shaft; 4 . input shaft bearings; 5 . lower disk; 6. upper disk; 7. upper or driven shaft; 8. upper shaft bearings; 9. torque sensor; and 10 . toothed belt drive with $4: 1$ gear ratio. The electromagnetic coil, which consisted of approximately 1000 turns, was located around the disks with the coils encircling them, providing magnetic field lines parallel to the shafts. The MR fluid was loaded into the lower disk. The diameter of the disks was $116 \mathrm{~mm}$ and the gap between them was $1 \mathrm{~mm}$.

The input and output signals were read and recorded by an National Instruments (NI) USB-6281 data acquisition device with a sampling rate of $1 \mathrm{kHz}$.

The complete magnetorheological clutch is shown in Fig. 2. For future measurements, a 3-phase AC induction motor with a frequency inverter was installed to serve as an artificial load.

\subsection{Samples and Measurements}

A Hall effect sensor, located at the top of the upper disk, measured the magnetic field. An encoder was located at the bottom of the drive shaft of the clutch to measure the input speed. The control and measurement tasks were carried out by a NI USB-6281 data acquisition device controlled by LabVIEW software. The input speed and output torque were recorded. The MR fluid used was LORD MRF-122EG fluid diluted by $50 \mathrm{~m} / \mathrm{m} \%$ with silicone oil. 


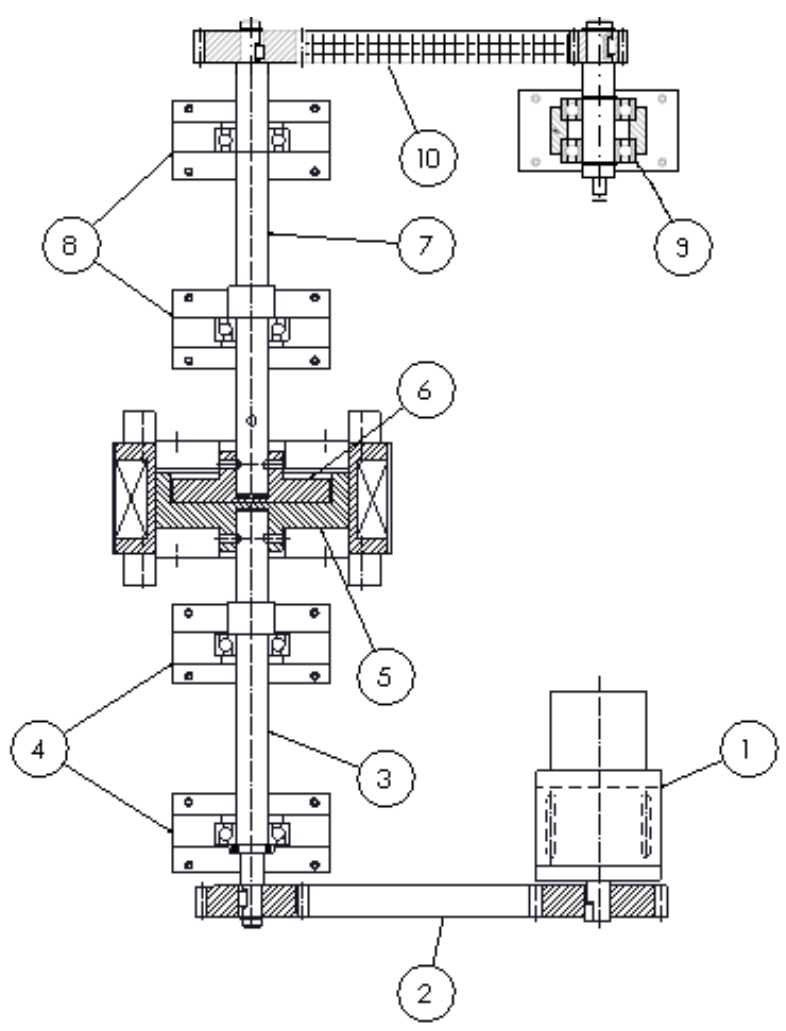

Figure 1: Model of a disk-type magnetorheological clutch

The output side of the clutch was fixed at the torque sensor with the intention of measuring the torque transmission time-constants, so the output speeds at both the sensor and driven shaft were zero. The measurement cycles, using a preset magnetic field, consisted of a 3second-long mixing phase in the absence of a magnetic field, followed by a 6 -second-long measurement period with the magnetic field turned on, and finally another 3second-long mixing phase, all at a constant speed. After the cycle, a new speed was set and a new cycle started. The speeds measured were 11.5, 17.5, 23.5, 29.5, 35.5, 40.5 , and $46.5 \mathrm{rpm}$. The magnetic induction was controlled by currents of $1.8,2.5,3.3$, and $4.4 \mathrm{~A}$ applied to the coil, thereafter the corresponding magnetic inductions were $114,144,173$, and $202 \mathrm{mT}$.

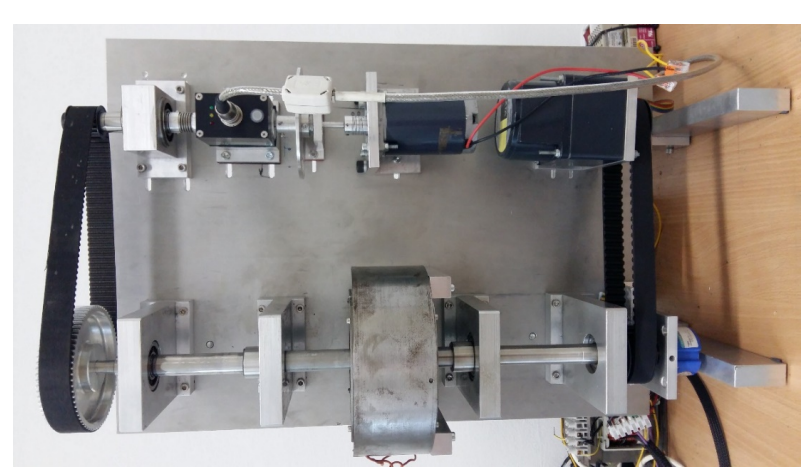

Figure 2: Complete magnetorheological clutch

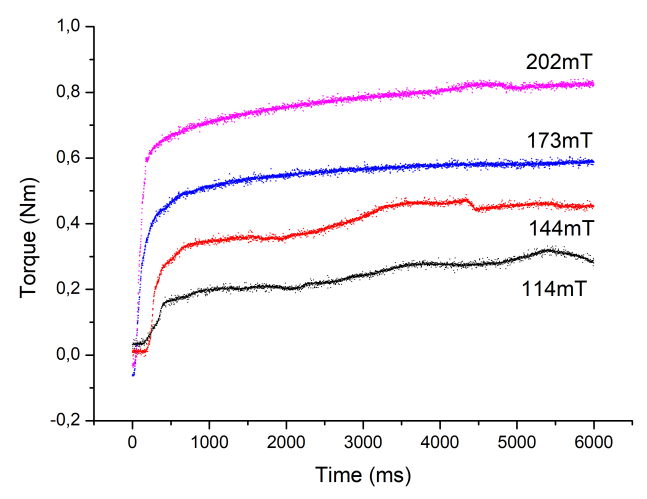

Figure 3: Transmission torque from when the magnetic field was turned on at a speed of $n=11.38 \mathrm{rpm}$ and using different magnetic inductions

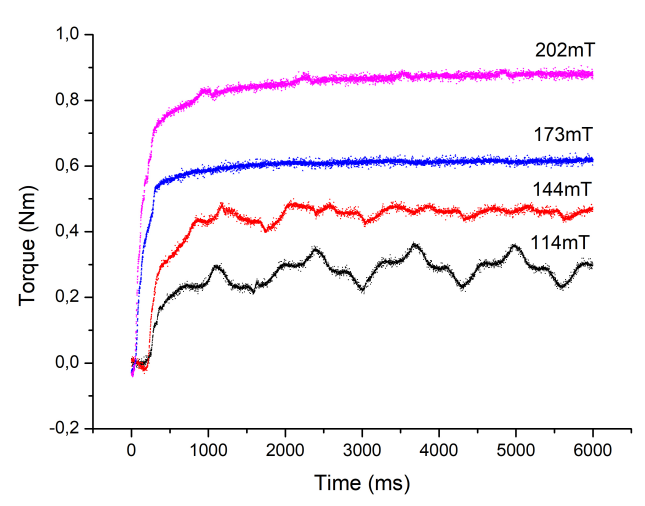

Figure 4: Transmission torque from when the magnetic field was turned on at a speed of $n=46.5 \mathrm{rpm}$ and using different magnetic inductions

\section{Results and Discussion}

\subsection{Experiments}

Using the aforementioned method, a series of 12 measurements were carried out at each speed and in each magnetic field by taking into consideration the uncertainty of the mechanical parts (toothed belts, bearings, etc.).

Examples of the measurements can be seen in Fig. 3 ( $n=11.38 \mathrm{rpm})$ and Fig. $4(n=46.50 \mathrm{rpm})$, as well as a periodicity due to the inaccuracies of the mechanical parts. The maximum output torque was $M=0.85 \mathrm{Nm}$.

\subsection{Calculation of time constants}

Time constants were determined by fitting an exponential function to the measured data:

$$
M(t)=A\left(1-e^{-\frac{t}{\tau}}\right)
$$

where $M$ denotes the transmission torque, $t$ represents the time, and $\tau$ stands for the time constant. The 


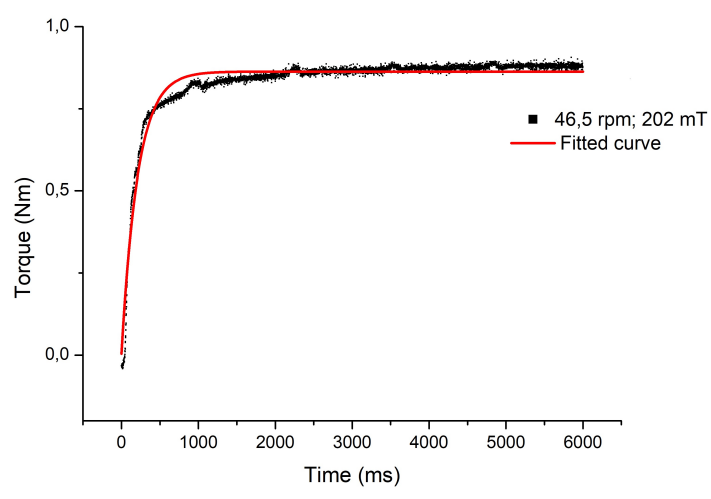

Figure 5: CFitted curve of measurements at a speed of $n=46.5 \mathrm{rpm}$ and a magnetic induction of $B=202 \mathrm{mT}$

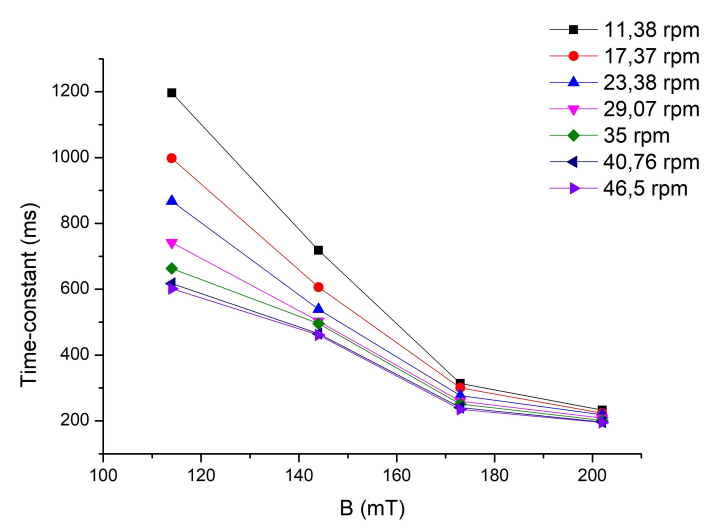

Figure 6: Time constants as a function of magnetic induction at different speeds

fitting was carried out according to the measurements. An example of the fitting is shown in Fig. 5.

The fitted curve correlates well with the measurement data. The results of the fitting were averaged to obtain the time constants for the applied magnetic inductions and rotational speeds. The time constants are shown in Fig. 6 as a function of magnetic induction. The measured time constants took into account the whole system, including the effects of the MR fluid as well as mechanical parts.

By increasing the magnetic field strength, the time constants decreased. In the weakest magnetic field and at the lowest speed, the time constant was extremely high, greater than 1 second to be exact, due to the characteristics of the fluid.

The time constants as a function of the speeds are shown in Fig. 7. Increasing the speed also resulted in a reduction in the time constant that was less significant than in stronger magnetic fields. In strong magnetic fields, the influence of the speed on the time constants was insignificant, therefore, its effect was almost negligible.

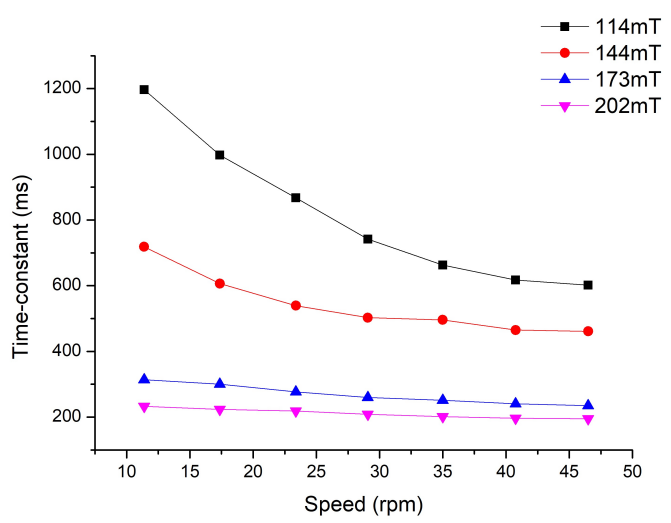

Figure 7: Time constants as a function of speed using different magnetic inductions

\section{Conclusion}

Based on the measurement results, the torque transmission time-constants for our magnetorheological clutch using the MR fluid were obtained. The time constants differed greatly from the response times of a magnetorheological fluid due to the inertia of the mechanical components. In the future, the influence of the mechanical parts on the time constants will be measured.

\section{Acknowledgements}

This research was supported by the European Union and co-financed by the European Social Fund under the project EFOP-3.6.2-16-2017-00002.

\section{REFERENCES}

[1] Rankin, P. J.; Ginder, J. M.; Klingenberg, D. J.: Electro- and magneto-rheology. Current Opinion in Colloid \& Interface Science, 1998, 3(4), 373-381 DOI: 10.1016/s1359-0294(98)80052-6

[2] Olabi, A. G. ; Grunwald, A.: Design and application of magneto-rheological fluid, Mater. Des., 2007, 28(10), 2658-2664 DOI: 10.1016/j.matdes.2006.10.009

[3] Mazlan, S. A. ; Ekreem, N. B.; Olabi, A. G.: An investigation of the behaviour of magnetorheological fluids in compression mode, J. Mater. Process. Technol., 2008, 201(1-3), 780-785 DOI: 10.1016/j.jmatprotec.2007.11.257

[4] Lampert, S. G. E. ; van Ostayen, R. A. J.: Experimental results on a hydrostatic bearing lubricated with a magnetorheological fluid, Curr. Appl. Phys., 2019, 19(12), 1441-1448 DOI: 10.1016/j.cap.2019.09.004

[5] Törőcsik, D.: Some Design Issues of Multi-Plate Magnetorheological Clutches, Hungarian J. Ind. Chem., 2011, 39(1), 41-44 https://mk. uni-pannon. hu/hjic/index.php/hjic/article/view/380

[6] Rabinow, J.: The Magnetic Fluid Clutch, Trans. Am. Inst. Electr. Eng., 1948, 67(2), 1308-1315 DOI: 10.1109/t-aiee.1948.5059821 
[7] Decsi, P.; Mester, S.; Szalai, I.: Tárcsás magnetoreológiai tengelykapcsoló modellezése, a rendszer időbeli viselkedésének vizsgálata, OGÉT XXVI. Nemzetközi Gépészei Konferencia 2018, 91-94 